\title{
Preparation and Characterization of Some Nanometal Oxides Using Microwave Technique and Their Application to Cotton Fabrics
}

\author{
M. Gouda, ${ }^{1,2}$ A. Aljaafari, ${ }^{1}$ Y. Al-Fayz, ${ }^{1}$ and W. E. Boraie ${ }^{1,3}$ \\ ${ }^{1}$ College of Science, King Faisal University, Al-Hassa, Saudi Arabia \\ ${ }^{2}$ Textile Research Division, National Research Center, Dokki, Cairo, Egypt \\ ${ }^{3}$ Chemistry Department, Faculty of Science, Ain Shams University, Abbassia, Cairo, Egypt
}

Correspondence should be addressed to M. Gouda; mgoudaam@kfu.edu.sa

Received 20 September 2014; Accepted 2 February 2015

Academic Editor: Nurit Beyth

Copyright (C) 2015 M. Gouda et al. This is an open access article distributed under the Creative Commons Attribution License, which permits unrestricted use, distribution, and reproduction in any medium, provided the original work is properly cited.

The objective of this paper is the synthesis of some nanometal oxides via microwave irradiation technique and their application to augment multifunctional properties of cotton fabric. Cotton fabrics containing nanometal oxides were prepared via a thiolmodification of cotton fabric samples and then dipped into the metal salt solutions precursors and transferred to the microwave oven. The surface morphology and quantitative analysis of the obtained modified cotton fabrics containing nanometal oxides were studied by scanning electron microscopy coupled with high energy dispersive X-ray (SEM-EDX). The shape and distribution of nanometal oxide inside the fabric samples were analyzed by transmission electron microscopy of cross-section fabric samples. The iron oxide nanoparticles had a nanosphere with particle size diameter 15-20 nm, copper oxide nanoparticles had a nanosphere with particle size diameter $25-30 \mathrm{~nm}$, and cobalt oxide nanoparticles had a nanotube-like shape with a length of 100-150 nanometer and a diameter of $\sim 58$ nanometer, whereas the manganese oxide nanoparticles had a linear structure forming nanorods with a diameter of 50-55 nanometer and a length of 70-80 nanometers. Antibacterial activity was evaluated quantitatively against grampositive bacteria such as Staphylococcus aureus and gram-negative bacteria such as Escherichia coli, UV-protection activity was analyzed using UV-DRS spectroscopy, and flame retardation of prepared fabric samples was evaluated according to the limiting oxygen index (LOI). Results revealed that the prepared fabric sample containing nanometal oxide possesses improved antibacterial, LOI, and UV-absorbing efficiency. Moreover, the metal oxide nanoparticles did not leach out the fabrics by washing even after 30 laundering washing cycles.

\section{Introduction}

Recently, much attention has been paid to the preparation and applications of nanometal oxides onto cotton substrate due to their promising applications [1-4]. The nanometal oxides deposited on cotton fabrics have shown splendid antimicrobial behavior towards gram-positive and gram-negative bacteria [4-7]. The researchers also indicated that the coated fabrics show enhanced protection against UV-radiation [6]. There is an increase in the cognizance around the usage of antiseptic textiles in the practice of therapeutic garments, protecting clothes, and bedspreads to reduce the chance of disease originating in a hospital infections [3, 8]. Metal nanoparticles are greatly more effective than bigger particles for the reason of their greater surface area. They moreover show distinctive physical and chemical properties [9]. Textile fabrics treated with silver nanoparticles to enhance antimicrobial activity have been developed [10]. Nanocopper oxides are very effective in adding antibacterial property to fabrics $[4,5]$. Furthermore, applications of these antibacterial fabrics on to the skin of animal confirmed that the fabrics do not have skin irritation properties [11]. Three common methods existed to precipitate the nanometal oxides into the cotton fabrics. First method was that nanometal oxides were prepared and then 
coated onto cotton fabrics just by pad-dry-cure technique [12, 13]. The second method was to apply the ultrasonic radiation as an active system for the precipitation of nanometal oxides onto the surface of cotton fabrics and further substrates $[4,5$, $14,15]$. The third method was via thermal chemical treatment [3].

Moreover, the utilization of nanomaterials in textile materials has involved significant attention owing to their unique physicochemical goods and their prospective uses. For instance, nano- $\mathrm{TiO}_{2}$ was used to augment of multifunctional properties of cotton fabrics, for example, ultraviolet-blocking, self-cleaning, and antiseptic properties [16-21]; $\mathrm{ZnO}$ nanoparticles have been applied in the textile industry for UV-protection and antibacterial assets and utilized in medical garments and shielding textiles [20, 21]. For an extended period, silver nanoparticles are nonhazardous, strong antiseptic which can eliminate more than 650 bacteria, virus, and fungi types. Consequently, silver nanoparticles interest a growing extent of scientific and manufacturing attention from fields such as textile science [21,22].

In recent years, noble metal nanoparticles have been used in antibacterial textile finishing. The ions which are produced from metal nanoparticles interact with sulfur-containing proteins in bacterial cell, which influence bacterial cell viability [23]. The noble metal nanoparticles slowly oxidize to release ions that react with the bacterial cells. This process conveys strong antibacterial effects toward pathogenic microorganisms for a long period.

Furthermore, direct synthesis/growth of metal nanoparticles on substrates is attracting a considerable interest mainly to address various challenges associated with the immobilization of preformed metal nanoparticles on different kinds of substrates. Such nanocomposite materials are important for their potential applications in optics, electronic devices, catalysis, sensors, medical applications, and so forth [24-28]. For example, antibacterial properties of polymer-supported silver nanoparticles are the subject of extensive studies for their applications in antimicrobial filters [29], tissue scaffolds, body wall repairing substances $[28,30,31]$, and antibacterial packaging materials for preventing bacterial infection in foodstuffs [28, 32].

Although, there exists a deep-rooted procedure for the synthesis of nanometal oxides, this procedure is required to progress in extra-active approaches for preparation including easy preparation processes with low time of reaction. The usage of microwave supported preparation is mostly vital in this concern. It has been indicated that microwave radiation can successfully govern the size spreading in a thinner range in a shorter time of reaction than the traditional heating system owing to regular and fast heating in the nanomaterials synthesis [33-35]. Additionally, microwave irradiation offers straight heating, self-regulation of heat diffusion and transmission. The thorough microwave environment contact by reactants through the materials creation is slightly uncertain and hypothetical [33]. Nevertheless, energy transfer from the microwaves to the materials is completed through the interaction of microwave energy with water or other solvents with high dielectric constant or solvents molecules with large dipole moments [36].
The objective of this work is the in situ synthesis of nanometal oxides such as nanoiron oxide, nanocoper oxide, nanocobalt oxide, and nanomanganese oxide using microwave irradiation as an energy source and the surface morphologies of the resulting treated cotton fabrics will be investigated by scan electron microscopy coupled with EDX and the distribution of prepared metal oxide nanoparticles inside the treated fabric samples will be characterized by transition electron microscopy of cross-section area of treated cotton fabric samples. Moreover, the properties of prepared cotton fabric samples such as antibacterial activity, UV-protection, and flame retardation will be evaluated. Furthermore, the durability of metal nanoparticles inside the cotton fabric samples at different washing cycles will be examined as the bacteriostasis of the treated cotton fabric.

\section{Experimental Methods}

2.1. Materials. Desized, bleached, and scoured cotton fabrics $\left(100 \mathrm{~g} / \mathrm{m}^{2}\right)$ were supplied by El-Mehalla for Spinning and Weaving Company, Egypt. Mercaptoacetic acid and paratoluene sulphonic acid were received from Sigma-Aldrich and were 99-99.9\% pure. Cobalt chloride, manganese chloride, iron chloride, and copper chloride were obtained from Sigma-Aldrich. Wholly all substances were used as analytical grade.

\subsection{Preparation of Thiol-Modified Cotton Fabrics. Cotton} fabrics were padded in solution containing $10 \%(\mathrm{v} / \mathrm{v})$ of mercaptoacetic acid in the presence of para-toluene sulphonic acid as a catalyst and squeezed between two rollers at $100 \%$ wet pick-up; the padded and squeezed cotton fabrics were cured at $130^{\circ} \mathrm{C}$ for $15 \mathrm{~min}$ using laboratory padder. The cured cotton fabrics were washed away with sufficient water to wash out the soluble impurities and dried out in an oven dryer at $50^{\circ} \mathrm{C}$ for overnight. In thiol modification of the cotton fabric, the hydroxyl groups were changed into mercaptoacetate groups as shown in Scheme 1.

2.3. In Situ Preparation of Metal Nanoparticles on the ThiolModified Cotton Fabric. Before the synthesis of nanometal oxides started, the thiol-modified cotton fabrics chelated with metal salt were prepared. This was done by dipping the modified cotton fabrics into a conical flask containing $100 \mathrm{~mL}$ of $1 \mathrm{~mm} \mathrm{FeCl}_{3}, \mathrm{CuCl}_{2}, \mathrm{CoCl}_{2}$, and $\mathrm{MnCl}_{2}$ solutions separately. The flasks were shaken overnight using Bench-top Shaker TZ-A Shanghai Hengyue Medical Instruments Co. Ltd. Dipped fabric samples were squeezed at $100 \%$ wet pickup. Modified cotton fabrics containing metal salts were then placed in the microwave oven (MARS6, CEM microwave systems CEM GmbH, Germany) operating at a power of $1800 \mathrm{~W}$ and frequency $2455 \mathrm{MHz}$ and subjected to microwave irradiation at $100^{\circ} \mathrm{C}$ for $5 \mathrm{~min}$. Upon microwave irradiation, the cotton fabric samples gained a color corresponding to each nanometal oxide. The fabric samples containing metal nanoparticles obtained were washed with double distilled and deionized water and then dried in an oven at $70^{\circ} \mathrm{C}$ for $1 \mathrm{~h}$. 


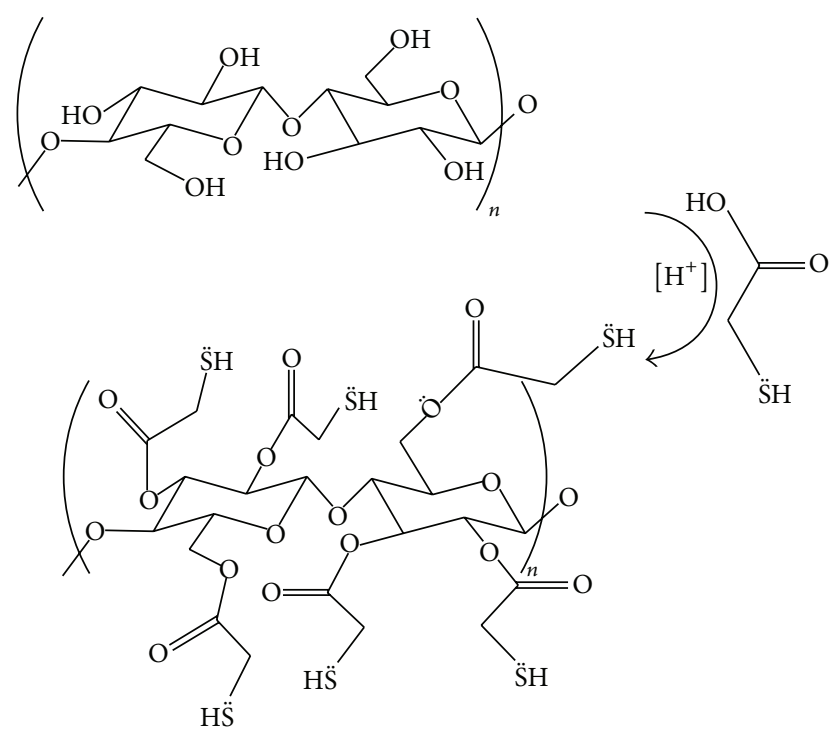

SCHEME 1: Thiol modification of cotton fabric using mercaptoacetic acid. Thiol modification of cellubiose (basic structural repeating unit of cellulose) is shown here for clarity.

2.4. Characterization. The presence of the thiol group in the cotton fabric was confirmed with FT-IR spectra using FT-IR (Shimadzu Scientific Instrument FT-IR-8400S) with spectral range $4000-600 \mathrm{~cm}^{-1}$. Spectra were collected with a resolution of $0.9-1.0 \mathrm{~cm}^{-1}$ and given as ratio of 200 single beam scans to the same number of background scans in pure $\mathrm{KBr}$. $\mathrm{KBr}$ was ground with the sample to fine powder. The amount of sulfur group was quantitatively estimated by means of elemental analyzer (FISON instrument model 1108). The morphology of cotton fabrics modified with mercaptoacetic acid containing metal oxide nanoparticles was considered by JOEL JXA-840-A electron probe microanalyzer-scanning electron microscope (SEM) and energy dispersive X-ray analysis (EDX). Further elemental analysis and quantification of metal oxide nanoparticles were done with EDX. The real metal oxide nanoparticles contents were determined by atomic absorption spectroscopy (Varian SpectrAA-220) with graphite furnace accessory and equipped with deuterium arc background corrector according to (APHA 2005). For this, suitable quantities of modified cotton fabric samples containing metals nanoparticles were digested in $75 \%$ concentrated $\mathrm{H}_{2} \mathrm{SO}_{4}$ at room temperature for $24 \mathrm{~h}$. Moreover, modified cotton fabric samples containing metals nanoparticles were characterized using TEM images of the cross-section of prepared fabric samples $[37,38]$. Limiting oxygen index (LOI) was determined according to the standard oxygen index test (ASTM D2863-95).

2.5. Antimicrobial Activity. Antibacterial properties of untreated cotton fabrics and thiol-modified cotton fabrics containing different metal nanoparticles ( $\mathrm{Fe}, \mathrm{Cu}, \mathrm{Co}$, and $\mathrm{Mn}$ ) were quantitatively evaluated against gram-positive bacteria (Staphylococcus aureus) and gram-negative bacteria (Escherichia coli) according to the standard test method used to measure the reduction rate in the number of colonies formed [39], as follows: $1 \mathrm{~g}$ fabric sample was dipped into a test tube containing the bacteria culture solution in which the bacteria concentration was $2.5 \times 10^{5} / \mathrm{mL}$. The test tubes were shaken at $37^{\circ} \mathrm{C}$ for $2 \mathrm{~h}$ on a rotary shaker at $100 \mathrm{rpm}$ and $1: 100$ dilutions of the test solutions were made. One milliliter of the diluted test solution was poured onto agar broth and incubated at $35^{\circ} \mathrm{C}$ for $24 \mathrm{~h}$ and the number of colonies in the agar broth was calculated using the following equation:

$$
\begin{aligned}
& \text { Reduction rate }(\%) \text { in the number of colony } \\
& =\left[\frac{(A-B)}{A}\right] \times 100
\end{aligned}
$$

where $A$ is the number of colonies before shaking and $B$ is the number of colonies after $1 \mathrm{~h}$ shaking.

2.6. UV-Penetration and Protection Measurement. The capability of a fabric to block UV-radiation is assumed via the ultraviolet protection factor (UPF) values. UPF values of cotton fabric samples containing nanometal oxides were obtained using M350 UV-visible spectrophotometer (SDL/ATLAS) according to Australian-New Zealand Standard AS/NZS 4399:1996. A UPF value of $15-24$ is categorized as good protection, 25-39 as very good protection, and above 40 as excellent protection against solar UV-radiation [40].

2.7. Washing Fastness. Washing fastness tests were carried out on thiol-modified cotton fabrics containing metal nanoparticles according to AATCC test method 61(2A)-1996. Separately round of laundry consisted of five washes at $38^{\circ} \mathrm{C}$. The stability of the cotton fabrics containing metal nanoparticles was studied by antibacterial testing after 10, 20, and 30 washings with nonionic detergent.

\section{Result and Discussion}

3.1. FT-IR of Thiol-Cotton Fabrics. In thiol modification of the cotton fabric, the hydroxyl groups were changed into mercaptoacetate groups as shown in Scheme 1 which shows the degree of substitution of hydroxyl groups by mercaptoacetate groups. In addition, $2.5 \mathrm{wt} \%$ sulfur was detected in the thiolated cotton fabric by elemental analyzer.

These results indicated that 0.13 units of hydroxyl groups per glucose unit in the cellulose fiber were successfully converted to thiol groups. In this reaction scheme, para-toluene sulphonic acid acts as a catalyst and provides $\mathrm{H}^{+}$ions for successful completion of the reaction.

FT-IR spectra of the thiolated cotton fabric are presented in Figure 1 which reveals a carbonyl $(\mathrm{C}=\mathrm{O})$ stretch corresponding to an ester group at $1730 \mathrm{~cm}^{-1}$ formed by an esterification reaction of mercaptoacetic acid with hydroxyl group in cotton.

3.2. Nanoparticles Formation and Characterization. The formation of nanoparticles in in situ thiol-modified cotton fabrics was based on the chelation of metal ions with chelating sites of the cotton fabrics (thiol groups), followed by 
TABLE 1: Antibacterial activity of thiol-modified cotton fabrics containing different nanometal oxides.

\begin{tabular}{|c|c|c|c|c|}
\hline \multirow{3}{*}{ Fabric sample containing } & \multicolumn{4}{|c|}{ Antibacterial efficiency (\%) } \\
\hline & Exposure time $(0 \mathrm{hr})$ & Exposure time ( $2 \mathrm{hr}$ ) & Exposure time $(0 \mathrm{hr})$ & Exposure time ( $2 \mathrm{hr})$ \\
\hline & S. aureus & S. aureus & E. coli & E. coli \\
\hline Untreated cotton fabric & - & - & - & - \\
\hline FeNPs & 99.9 & 100 & 98.8 & 100 \\
\hline CuNPs & 99.7 & 100 & 98.5 & 100 \\
\hline CoNPs & 98.8 & 100 & 96.9 & 98.7 \\
\hline MnNPs & 97.9 & 100 & 95.0 & 97.8 \\
\hline
\end{tabular}

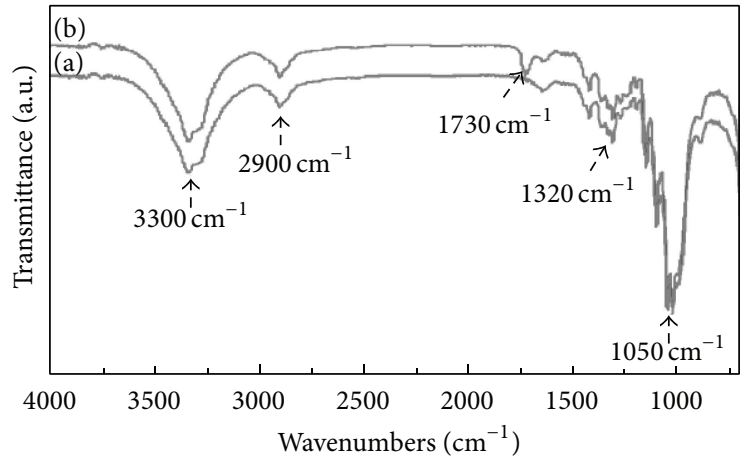

FIGURE 1: FT-IR spectra of (a) the unmodified cotton fabric and (b) thiol-modified cotton fabric.

microwave irradiation of the chelated metal ions, so that the $\mathrm{Fe}^{3+}, \mathrm{Cu}^{2+}, \mathrm{Co}^{2+}$, and $\mathrm{Mn}^{2+}$ chelating ions on thiol-modified cotton fabric samples oxidized by microwave irradiation into nanoiron oxide, nanocopper oxide, nanocobalt oxide, and nanomanganese oxide nanoparticles.

3.2.1. TEM Images. To approve the creation of nanoiron oxide, nanocopper oxide, nanocobalt oxide, and nanomanganese oxide into cotton fabrics, TEM analysis of cross-sectional samples was carried out for the prepared fabric samples. It is apparent from Figure 2 that nanometal oxides do not look likely to form agglomerates and are in good distribution inside the fabric owing to the steadiness of synthesized nanometal oxides, in the in situ cellulosic network. Figures 2(a) and 2(b) show that iron and copper oxide nanoparticles inside fabric samples looked like spherical particles and their diameters were $10-15 \mathrm{~nm}$ and $25-30 \mathrm{~nm}$ for nanoiron oxide and nanocopper oxide, respectively. TEM image for cross-section of fabric samples containing cobalt oxide nanoparticles is shown in Figure 2(c) which demonstrates that the nanoparticles had a nanotube-like shape. The length of the nanotube was 100-150 nm (mean length $\sim 130 \mathrm{~nm}$ ) and the diameter was $\sim 58 \mathrm{~nm}$. The synthesized cobalt oxide had a good nanotube structure and was stable. TEM image of cross-section of fabric samples containing manganese oxide nanoparticles formed is shown in Figure 2(d). Each particle was a linear nanorod structure with diameter of $50 \sim 55 \mathrm{~nm}$ and a length of $70 \sim$ $80 \mathrm{~nm}$.
3.2.2. SEM. The SEM images of thiol-modified fabric samples are shown in Figure 3 . The pictures represent obviously the presence of metal oxide NPs, on cotton fabric. Also, Figure 3 illustrates EDX spectra analysis of sample (a) (fabric containing iron nanoparticles), sample (b) (fabric containing copper nanoparticles), sample (c) (fabric containing cobalt nanoparticles), and sample (d) (fabric containing manganese nanoparticles), respectively. EDX analysis was used to determine the composition of the samples. The strong signals from $\mathrm{Fe}, \mathrm{Cu}, \mathrm{Co}$, and $\mathrm{Mn}$ atoms confirm the presence of these metals in the in situ cotton fabric samples. Sample 1 contained $33.25 \mathrm{wt} \% \mathrm{Fe}$, sample 2 contained $19.33 \mathrm{wt} \% \mathrm{Cu}$, sample 3 contained $16.7 \mathrm{wt} \% \mathrm{Co}$, and sample 4 contained $13.4 \mathrm{wt} \%$ Mn on the cotton fabric, respectively, representing significant loading of metal nanoparticles on the cotton fabric. This is more clearly confirmed in the analysis of the nanometal oxide contents of the fabric samples by AA spectral analysis. Metal contents in the thiol-modified cotton fabric samples were 33.2\% (wt) Fe, 19.33 wt \% Cu, 16.7 wt $\%$ Co, and 13.4 wt $\% \mathrm{Mn}$. These differences in the contents of nanometal oxides in the modified cotton fabric samples are according to the IrvingWilliams series mentions on the comparative stabilities of complexes made by a metal ion. For high-spin complexes of the divalent ions of first-row transition metals, the stability constant for the complex creation follows the decreasing order: $\mathrm{Mn}$ (II) $<\mathrm{Co}$ (II) $<\mathrm{Cu}(\mathrm{II})<\mathrm{Fe}(\mathrm{III})$. This order was established to hold for an extensive selection of ligands [41]. There are descriptions that are estimated commonly to describe the series. (i) The ionic radius is estimated to decrease frequently for $\mathrm{Mn}^{2+}$ to $\mathrm{Fe}^{3+}$. This is the regular periodic tendency and would explain the common increase in stability. (ii) The crystal field stabilization energy (CFSE) increases from zero for manganese(II) to a maximum at iron(III). This makes the complexes more and more stable.

3.3. Antimicrobial Activity. All fabric samples presented high antibacterial efficiency (Table 1), with all fabrics revealing an effective antibacterial effect against $S$. aureus and E. coli bacteria; almost all bacteria were killed after $2 \mathrm{~h}$ of contact. In addition, at zero contact time (i.e., antibacterial activity of the fabric sample was investigated after 1 min contact), the fabric samples displayed the ability to destroy bacteria and because of the rapid diffusion of bacteria through the fabric samples and contact with the large amount of nanoparticles many bacteria were killed even after a few seconds. Table 1 reveals that antibacterial activity of modified cotton fabric sample loaded 


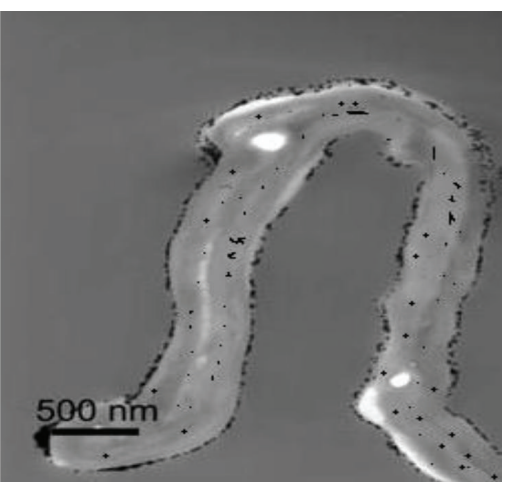

(a)

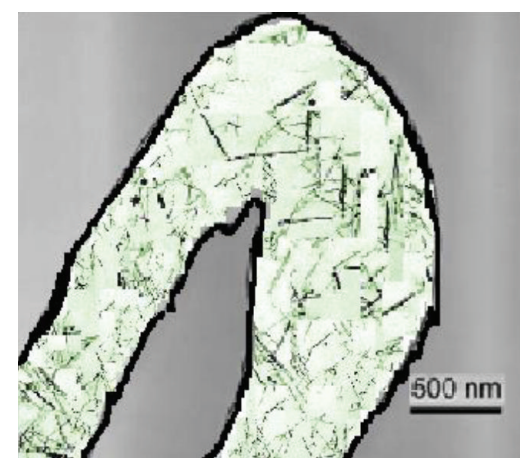

(c)

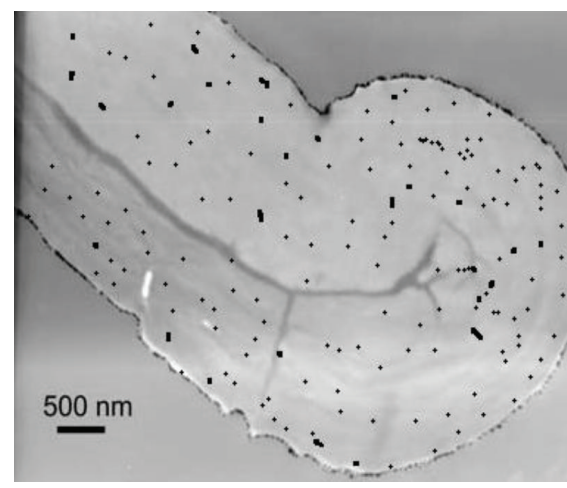

(b)

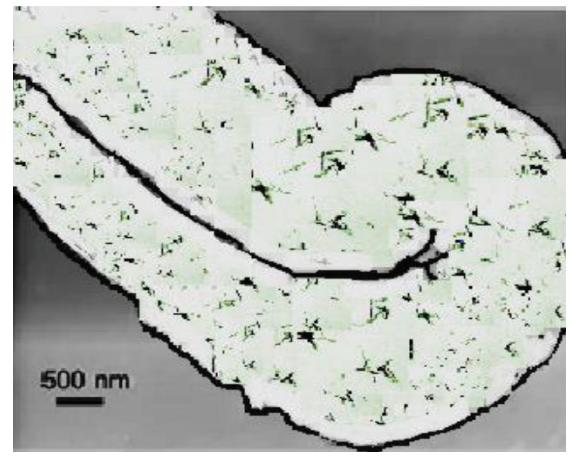

(d)

FIgURE 2: TEM images of cross-section of thiol cotton fabric containing (a) FeNPs, (b) CuNPs, (c) CoNPs, and (d) MnNPs.

with nanometal oxides have the following decreasing order: iron oxide nanoparticles $>$ copper oxide nanoparticles $>$ cobalt oxide nanoparticles $>$ manganese oxide nanoparticles $>$ untreated cotton fabric and this may be attributed to the fact that [42] the fast penetration of nanoparticles into bacteria membranes depends on the particles sizes which follow the decreasing order (FeNPs $<$ CuNPs $<$ CoNPS $<$ MnNPs) and the penetration of these nanoparticles is majorly due to oxidative strain and reasons of distraction of the cell membrane. The antibacterial medications and antibiotics improve oxidative strain by making reactive oxygen species [43]. Reactive oxygen species (ROS) can cause destruction of proteins and DNA in bacteria [44]. This bactericidal asset has been demonstrated from silver metals by Park et al. [45]. So the higher antibacterial action of FeNPs toward the S. aureus and E. coli could be owing to the synergistic influence of the phytochemicals, magnetic properties, and proliferation of ROS by FeNPs more than the other nanoparticles.

3.4. UV-Penetration and Protection Measurement. To evaluate the potential effectiveness of certain metal nanoparticles chemically bonded to the in situ cotton fabrics samples for enhancing the UPF values, four metal nanoparticles such as FeNPs, CuNPs, CoNPs, and MnNPs were used for their capability to elevate the intrinsic UV-blocking toward the injurious UV-irradiation. Results of Table 2 indicate that (i) the presence of metal nanoparticles inside the cotton fabric samples increases the UPF values compared to the cotton
TABLE 2: Effect of metal nanoparticles type and content on UV protective factor properties of prepared fabrics.

\begin{tabular}{lcc}
\hline Metal type & Metal content & UPF rating \\
\hline Untreated cotton fabric & 0 & 6.0 \\
Cotton fabric-FeNPs & $33.25 \mathrm{wt} \%$ & $>50$ \\
Cotton fabric-CuNPs & $19.33 \mathrm{wt} \%$ & 50 \\
Cotton fabric-CoNPs & $16.74 \mathrm{wt} \%$ & 45 \\
Cotton fabric-MnNPs & $13.37 \mathrm{wt} \%$ & 40 \\
\hline
\end{tabular}

TABLE 3: LOI values of the prepared cotton fabric samples containing different metal oxide nanoparticles.

\begin{tabular}{lc}
\hline Nanoparticles & LOI value \\
\hline Untreated cotton fabric & 15.6 \\
Cotton fabric-FeNPs & 45.12 \\
Cotton fabric-CuNPs & 30.8 \\
Cotton fabric-CoNPs & 26.4 \\
Cotton fabric-MnNPs & 24.8 \\
\hline
\end{tabular}

fabrics without treatment, (ii) the degree of upgrading in the UV-protection properties is estimated via the kind of metal nanoparticles and follows the order: FeNPs $>$ CuNPs $>$ CoNPs $>$ MnNPs $>$ cotton fabric without nanometal oxide, and (iii) the difference in the UV-protecting command of prepared fabric samples in existence of the abovementioned nanometal oxides reveals the variances between them in 

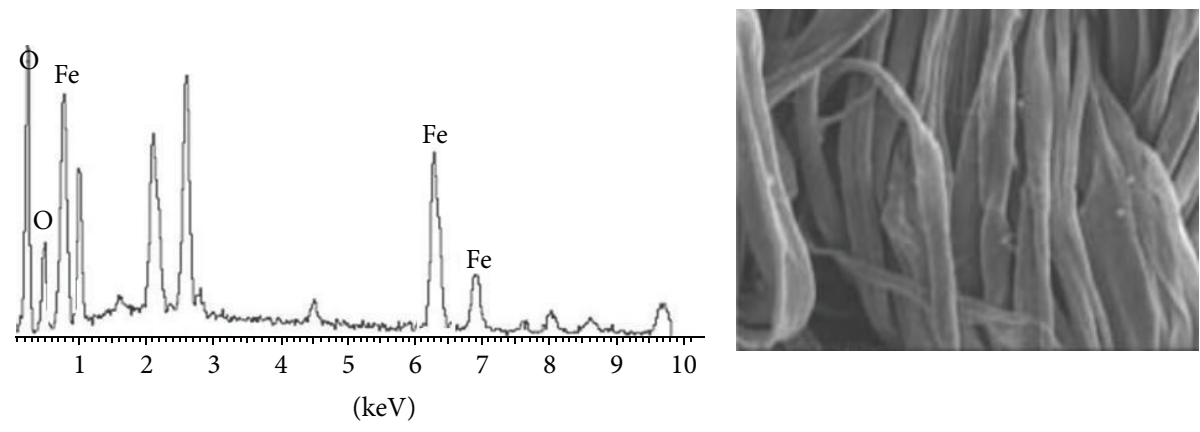

Full scale 401 cts cursor: 0.000

(a)
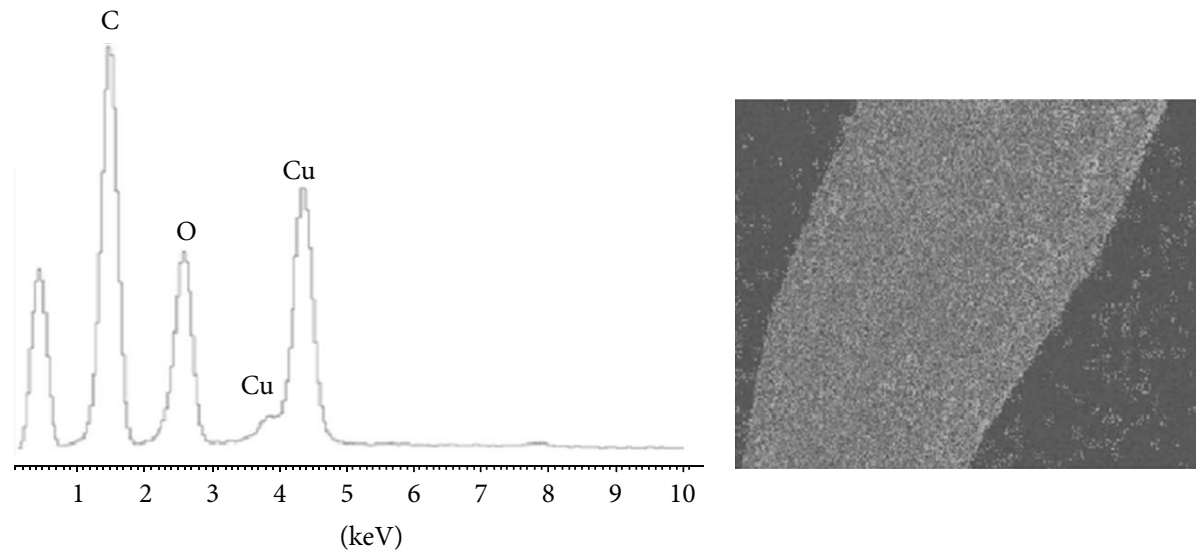

Full scale 401 cts cursor: 0.000

(b)
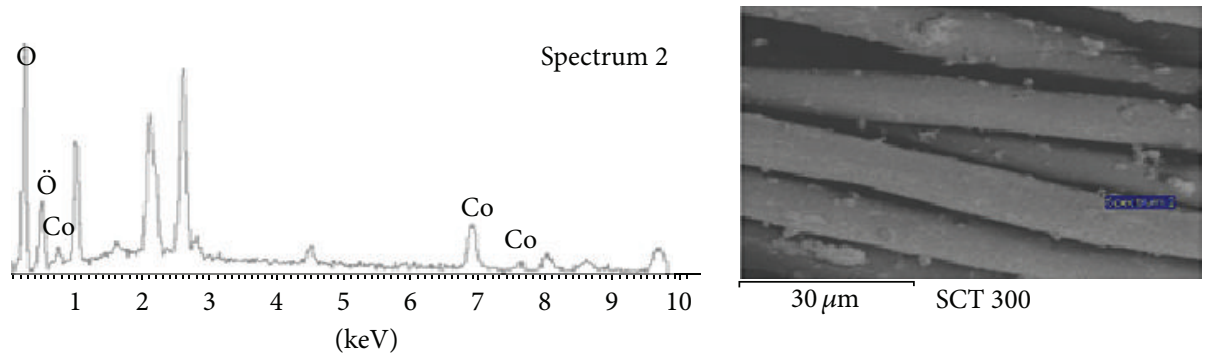

Full scale 401 cts cursor: 0.000

(c)
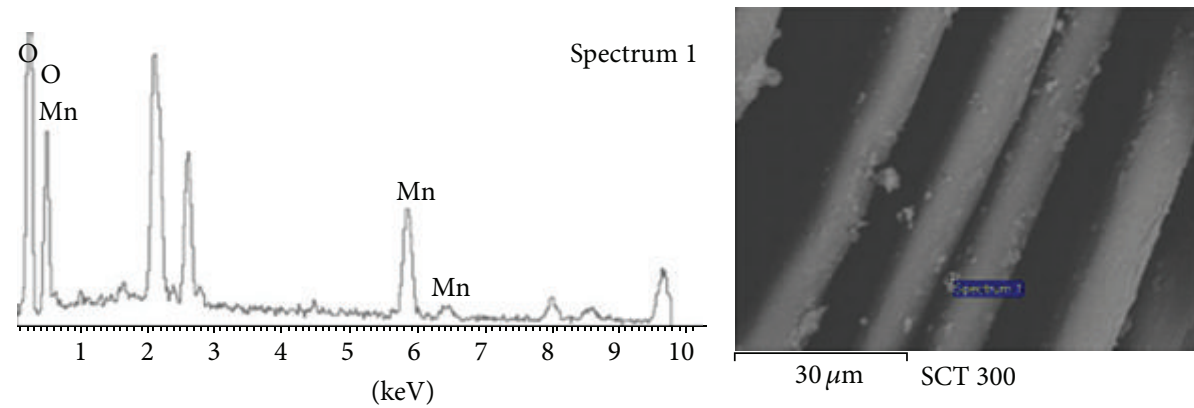

Full scale 401 cts cursor: 0.000

(d)

FIGURE 3: SEM micrograph spectroscopy and EDX analysis of thiol-modified cotton fabrics containing (a) FeNPs, (b) CuNPs, (c) CoNPs, and MnNPs. 
TABLE 4: Antibacterial reduction percentages of cotton samples containing metals nanoparticles: sample 1 (FeNPs), sample 2 (CuNPs), sample 3 (CoNPS), and sample 4 (MnNPs).

\begin{tabular}{|c|c|c|c|c|c|c|c|c|}
\hline \multirow{2}{*}{ Number of washings } & \multicolumn{2}{|c|}{ Sample 1} & \multicolumn{2}{|c|}{ Sample 2} & \multicolumn{2}{|c|}{ Sample 3} & \multicolumn{2}{|c|}{ Sample 4} \\
\hline & S. aureus & E. coli & S. aureus & E. coli & S. aureus & E. coli & S. aureus & E. coli \\
\hline 0 & 100 & 100 & 100 & 100 & 100 & 98.7 & 100 & 97.8 \\
\hline 10 & 99.5 & 97.8 & 98.4 & 96.6 & 97.3 & 96.5 & 98.6 & 95.3 \\
\hline 20 & 99.5 & 97.8 & 98.4 & 96.6 & 97.3 & 96.5 & 98.6 & 95.3 \\
\hline 30 & 99.5 & 97.8 & 98.4 & 96.6 & 97.3 & 96.5 & 98.6 & 95.3 \\
\hline
\end{tabular}

molecular weight, content, particle size, surface area, position and the degree of spreading, obstructive assets, and absorbing capability [46].

3.5. Flame Retardation. The limited oxygen index (LOI) values of prepared fabric are obtained in Table 3. The data so found display that the prepared fabric samples containing metal oxide nanoparticles have LOI values of 45.12, 30.8, 26.4, and 24.8, for fabric samples containing FeNPs, CuNPs, CoNPs, and MnNPs, respectively. This may be due to the capability of these nanoparticles to form blocks that prevent Linder-directed contact with heat. The LOI value of FeNPs is greater than that of the other nanoparticles. This is due to the fact that the FeNPs have a good capability to absorb heat in comparison to the particle under investigation. LOI values of prepared fabric samples containing metal oxide nanoparticles follow a decreasing order: cotton fabric sample containing FeNPs $>$ cotton fabric sample containing CuNPs $>$ cotton fabric sample containing CoNPs $>$ cotton fabric sample containing MnNPs > untreated cotton fabric sample.

3.6. Washing Fastness of Antibacterial Property. The washing fastness of sample 1 (fabric containing iron nanoparticles), sample 2 (fabric containing copper nanoparticles), sample 3 (fabric containing cobalt nanoparticles), and sample 4 (fabric containing manganese nanoparticles) was assessed under different conditions including no washes and 10, 20, and 30 washes. The antibacterial action of each sample against gram-positive and gram-negative bacteria was investigated after $2 \mathrm{~h}$ exposure based on the AATCC 61(2A)-1996 washing test method. Table 4 shows that the antibacterial activity of fabric samples at 0 washing cycles was slightly greater than that of the fabric samples at the other washing cycles and this is attributed to the presence of slight amount of nonchelated nanoparticles which are present on the surface of the cotton fabrics. Repeating washing cycles (10 to 30) had no decreasing effect on the antibacterial activity due to nanoparticles which are not leached out the fabric samples because there is a chemical reaction between thiol groups on cotton fabrics and the nanoparticles. Therefore, by these chemical bonds, the nanoparticles did not leach out the fabrics by washing even after 30 laundering washing cycles, indicating excellent durability of the nanotreatment fabric samples against washing.

\section{Conclusion}

Multifunctional properties of cotton fabrics such as antibacterial activity, UV-protection, and flame retardation were developed by in situ preparation of nanometal oxides such as iron oxide, copper oxide, cobalt oxide, and manganese oxide nanoparticles into thiol-modified cotton fabric using microwave irradiation. Firstly, thiol-modified cotton fabrics were prepared by the treatment of cotton fabrics with mercaptoacetic acid in the presence of para-toluene sulphonic acid as a catalyst. Furthermore, in situ preparation of aforementioned nanometal oxides into modified cotton fabrics was obtained. Formed nanoparticles do not seem to form coagulates and were well spread inside the fabric; iron and copper oxide nanoparticles inside fabric samples looked like spherical particles and their diameters were 10-15 nm and 25$30 \mathrm{~nm}$ for iron oxide nanoparticles and copper oxide nanoparticles, respectively, while cobalt oxide nanoparticles had a nanotube-like shape. The length of the nanotube was 100$150 \mathrm{~nm}$ and the diameter was $\sim 58 \mathrm{~nm}$ and manganese oxide nanoparticles formed had a linear nanorod structure with a diameter of $50 \sim 55 \mathrm{~nm}$ and a length of $70 \sim 80 \mathrm{~nm}$.

All prepared cotton fabric samples containing these nanometal oxides have high antibacterial efficiency, with an effective antibacterial effect against $S$. aureus and E. coli bacteria; almost all bacteria were killed after $2 \mathrm{~h}$ of contact. In addition, at zero contact time, the fabric samples displayed the ability of destroying bacteria. Antibacterial activities of modified cotton fabric samples loaded with nanometal oxides have the following decreasing order: iron oxide nanoparticles > copper oxide nanoparticles $>$ cobalt oxide nanoparticles $>$ manganese oxide nanoparticles $>$ untreated cotton fabric.

The presence of the aforementioned nanometal oxides nanoparticles inside the cotton fabric samples increases the UPF values and the degree of enhancement in the UV-blocking properties is estimated by the kind of metal nanoparticles and follows the following order: FeNPs $>$ CuNPs $>$ CoNPs $>$ MnNPs.

Prepared fabric samples containing metal oxide nanoparticles have LOI values of 45.12, 30.8, 26.4, and 24.8, for fabric samples containing FeNPs, CuNPs, CoNPs, and MnNPs, respectively. LOI values of prepared fabric samples containing metal oxide nanoparticles follow a decreasing order: cotton fabric sample containing FeNPs > cotton fabric sample containing CuNPs > cotton fabric sample containing 
CoNPs $>$ cotton fabric sample containing MnNPs > untreated cotton fabric sample.

The covalent bonds between the unhydroglucose unit of cotton fabrics and these nanometal oxides were imparted strong antibacterial action to the modified substrates against gram-positive (S. aureus) and gram-negative (E. coli) bacteria strains even after 30 successive home washing rounds.

\section{Conflict of Interests}

The authors declare that there is no conflict of interests regarding the publication of this paper.

\section{Acknowledgment}

The authors are grateful to the Dean of Scientific Research at King Faisal University for their financial support for this project work through project no. 130190.

\section{References}

[1] J. P. Borah, J. Barman, and K. C. Sarma, "Structural and optical properties of ZnS nanoparticles," Chalcogenide Letters, vol. 5, no. 9, pp. 201-208, 2008.

[2] H. Wang, A. Zakirov, S. U. Yuldashev, J. Lee, D. Fu, and T. Kang, "ZnO films grown on cotton fibers surface at low temperature by a simple two-step process," Materials Letters, vol. 65, no. 9, pp. 1316-1318, 2011.

[3] G. Borkow and J. Gabbay, "Copper, an ancient remedy returning to fight microbial, fungal and viral infections," Current Chemical Biology, vol. 3, no. 3, pp. 272-278, 2009.

[4] O. V. Abramov, A. Gedanken, Y. Koltypin et al., "Pilot scale sonochemical coating of nanoparticles onto textiles to produce biocidal fabrics," Surface and Coatings Technology, vol. 204, no. 5, pp. 718-722, 2009.

[5] I. Perelshtein, G. Applerot, N. Perkas et al., "CuO-cotton nanocomposite: formation, morphology, and antibacterial activity," Surface and Coatings Technology, vol. 204, no. 1-2, pp. 54-57, 2009.

[6] Ş. S. Uğur, M. Sarışık, A. H. Aktaş, M. Ç. Uçar, and E. Erden, "Modifying of cotton fabric surface with Nano-ZnO multilayer films by layer-by-layer deposition method," Nanoscale Research Letters, vol. 5, no. 7, pp. 1204-1210, 2010.

[7] R. Rajendra, C. Balakumar, H. A. M. Ahammed, S. Jayakumar, K. Vaideki, and E. Rajesh, "Use of zinc oxide nano particles for production of antimicrobial textiles," International Journal of Engineering, Science and Technology, vol. 2, no. 1, pp. 202-208, 2010.

[8] S. Wang, W. Hou, L. Wei, H. Jia, X. Liu, and B. Xu, "Antibacterial activity of nano- $\mathrm{SiO}_{2}$ antibacterial agent grafted on wool surface," Surface and Coatings Technology, vol. 202, no. 3, pp. 460-465, 2007.

[9] C. Y. Chen and C. L. Chiang, "Preparation of cotton fibers with antibacterial silver nanoparticles," Materials Letters, vol. 62, no. 21-22, pp. 3607-3609, 2008.

[10] N. Durán, P. D. Marcato, G. I. H. de Souza, O. L. Alves, and E. Esposito, "Antibacterial effect of silver nanoparticles produced by fungal process on textile fabrics and their effluent treatment," Journal of Biomedical Nanotechnology, vol. 3, no. 2, pp. 203-208, 2007.
[11] G. Borrow and J. Gabbay, "Putting copper into action: copperimpregnated products with potent biocidal activities," The FASEB Journal, vol. 18, no. 14, pp. 1728-1730, 2004.

[12] S. Anita, T. Ramachandran, R. Rajendran, C. Koushik, and M. Mahalakshmi, "A study of the antimicrobial property of encapsulated copper oxide nanoparticles on cotton fabric," Textile Research Journal, vol. 81, no. 10, pp. 1081-1088, 2011.

[13] B. Xu and Z. Cai, "Fabrication of a superhydrophobic ZnO nanorod array film on cotton fabrics via a wet chemical route and hydrophobic modification," Applied Surface Science, vol. 254, no. 18, pp. 5899-5904, 2008.

[14] A. Gedanken, "Using sonochemistry for the fabrication of nanomaterials," Ultrasonics Sonochemistry, vol. 11, no. 2, pp. 47$55,2004$.

[15] N. Perkas, G. Amirian, S. Dubinsky, S. Gazit, and A. Gedanken, "Ultrasound-assisted coating of nylon 6,6 with silver nanoparticles and its antibacterial activity," Journal of Applied Polymer Science, vol. 104, no. 3, pp. 1423-1430, 2007.

[16] M. Gouda and A. I. Aljaafari, "Augmentation of multifunctional properties of cellulosic cotton fabric using titanium dioxide nanoparticles," Advances in Nanoparticles, vol. 1, no. 3, pp. 2936, 2012.

[17] N. Burniston, C. Bygott, and J. Stratton, "Nano technology meets $\mathrm{TiO}_{2}$," Surface Coatings International Part A, vol. 87, no. 4, pp. 179-184, 2004.

[18] B. Fei, Z. Deng, J. H. Xin, Y. Zhang, and G. Pang, "Room temperature synthesis of rutile nanorods and their applications on cloth," Nanotechnology, vol. 17, no. 8, pp. 1927-1931, 2006.

[19] Z. Shi, K. G. Neoh, and E. T. Kang, "Antibacterial activity of polymeric substrate with surface grafted viologen moieties," Biomaterials, vol. 26, no. 5, pp. 501-508, 2005.

[20] S.-H. Choi, Y.-P. Zhang, A. Gopalan, K.-P. Lee, and H.-D. Kang, "Preparation of catalytically efficient precious metallic colloids by $\gamma$-irradiation and characterization," Colloids and Surfaces A: Physicochemical and Engineering Aspects, vol. 256, no. 2-3, pp. 165-170, 2005.

[21] M. Saito, "Antibacterial, deodorizing, and UV absorbing materials obtained with zinc oxide $(\mathrm{ZnO})$ coated fabrics," Journal of Coated Fabrics, vol. 23, pp. 150-164, 1993.

[22] H. J. Lee and S. H. Jeong, "Bacteriostasis and skin innoxiousness of nanosize silver colloids on textile fabrics," Textile Research Journal, vol. 75, no. 7, pp. 551-556, 2005.

[23] J. R. Morones, J. L. Elechiguerra, A. Camacho et al., "The bactericidal effect of silver nanoparticles," Nanotechnology, vol. 16, no. 10, pp. 2346-2353, 2005.

[24] G. A. Baker and D. S. Moore, "Progress in plasmonic engineering of surface-enhanced Raman-scattering substrates toward ultra-trace analysis," Analytical and Bioanalytical Chemistry, vol. 382, no. 8, pp. 1751-1770, 2005.

[25] G. B. Sergeev, Nanochemistry, Elsevier Science, Amsterdam, The Netherlands, 2006.

[26] J.-W. Kwon, S. H. Yoon, S. S. Lee, K. W. Seo, and I.-W. Shim, "Preparation of silver nanoparticles in cellulose acetate polymer and the reaction chemistry of silver complexes in the polymer," Bulletin of the Korean Chemical Society, vol. 26, no. 5, pp. 837840, 2005.

[27] E. M. Hetrick and M. H. Schoenfisch, "Reducing implantrelated infections: active release strategies," Chemical Society Reviews, vol. 35, no. 9, pp. 780-789, 2006.

[28] N. Drogat, R. Granet, V. Sol et al., "Antimicrobial silver nanoparticles generated on cellulose nanocrystals," Journal of Nanoparticle Research, vol. 13, no. 4, pp. 1557-1562, 2011. 
[29] M. Gouda, A. A. Hebeish, and M. A. Al-Omair, "Development of silver-containing nanocellulosics for effective water disinfection," Cellulose, vol. 21, no. 3, pp. 1965-1974, 2014.

[30] W. K. Son, J. H. Youk, T. S. Lee, and W. H. Park, "Preparation of antimicrobial ultrafine cellulose acetate fibers with silver nanoparticles," Macromolecular Rapid Communications, vol. 25, no. 18, pp. 1632-1637, 2004.

[31] Y. Wang, Q. Yang, G. Shan et al., "Preparation of silver nanoparticles dispersed in polyacrylonitrile nanofiber film spun by electrospinning," Materials Letters, vol. 59, no. 24-25, pp. 30463049, 2005.

[32] R. Tankhiwale and S. K. Bajpai, "Graft copolymerization onto cellulose-based filter paper and its further development as silver nanoparticles loaded antibacterial food-packaging material," Colloids and Surfaces B: Biointerfaces, vol. 69, no. 2, pp. 164-168, 2009.

[33] I. Bilecka, P. Elser, and M. Niederberger, "Kinetic and thermodynamic aspects in the microwave-assisted synthesis of $\mathrm{ZnO}$ nanoparticles in benzyl alcohol," ACS Nano, vol. 3, no. 2, pp. 467-477, 2009.

[34] J.-F. Zhu, Y.-J. Zhu, M.-G. Ma, L.-X. Yang, and L. Gao, "Simultaneous and rapid microwave synthesis of polyacrylamide-metal sulfide $\left(\mathrm{Ag}_{2} \mathrm{~S}, \mathrm{Cu}_{2} \mathrm{~S}, \mathrm{HgS}\right)$ nanocomposites," The Journal of Physical Chemistry C, vol. 111, no. 10, pp. 3920-3926, 2007.

[35] M. B. Mohamed, K. M. Abouzeid, V. Abdelsayed, A. A. Aljarash, and M. S. El-Shall, "Growth mechanism of anisotropic gold nanocrystals via microwave synthesis: formation of dioleamide by gold nanocatalysis," ACS Nano, vol. 4, no. 5, pp. 2766-2772, 2010.

[36] S. A. Galema, "Microwave chemistry," Chemical Society Reviews, vol. 26, no. 3, pp. 233-238, 1997.

[37] J. Gabbay, G. Borkow, J. Mishal, E. Magen, R. Zatcoff, and Y. Shemer-Avni, "Copper oxide impregnated textiles with potent biocidal activities," Journal of Industrial Textiles, vol. 35, no. 4, pp. 323-335, 2006.

[38] Y. Zhang, H. Ouyang, T. L. Chwee, S. Ramakrishna, and Z.M. Huang, "Electrospinning of gelatin fibers and gelatin/PCL composite fibrous scaffolds," Journal of Biomedical Materials Research, Part B: Applied Biomaterials, vol. 72, no. 1, pp. 156$165,2005$.

[39] O. Yuke, "Test method of antimicrobial finished fabrics," in Antimicrofinish, pp. 182-184, The Antimicrobial Finish Society of Japan Textiles, 1989.

[40] M. Srinivasan and B. M. Gatewood, "Relationship of dye characteristics to UV-protection provided by cotton fabric," Textile Chemist and Colorist \& American Dyestuff Reporter, vol. 32, no. 4, pp. 36-43, 2000.

[41] H. Irving and R. J. P. Williams, "The stability of transition-metal complexes," Journal of the Chemical Society, pp. 3192-3210, 1953.

[42] C. Lee, J. Y. Kim, W. I. Lee, K. L. Nelson, J. Yoon, and D. L. Sedlak, "Bactericidal effect of zero-valent iron nanoparticles on Escherichia coli," Environmental Science \& Technology, vol. 42, no. 13, pp. 4927-4933, 2008.

[43] M. A. Kohanski, M. A. DePristo, and J. J. Collins, "Sublethal antibiotic treatment leads to multidrug resistance via radicalinduced mutagenesis," Molecular Cell, vol. 37, no. 3, pp. 311-320, 2010.

[44] H. Sies, "Oxidative stress: oxidants and antioxidants," Experimental Physiology, vol. 82, no. 2, pp. 291-295, 1997.

[45] H.-J. Park, J. Y. Kim, J. Kim et al., "Silver-ion-mediated reactive oxygen species generation affecting bactericidal activity," Water Research, vol. 43, no. 4, pp. 1027-1032, 2009.
[46] A. Yadav, V. Prasad, A. A. Kathe et al., "Functional finishing in cotton fabrics using zinc oxide nanoparticles," Bulletin of Materials Science, vol. 29, no. 6, pp. 641-645, 2006. 

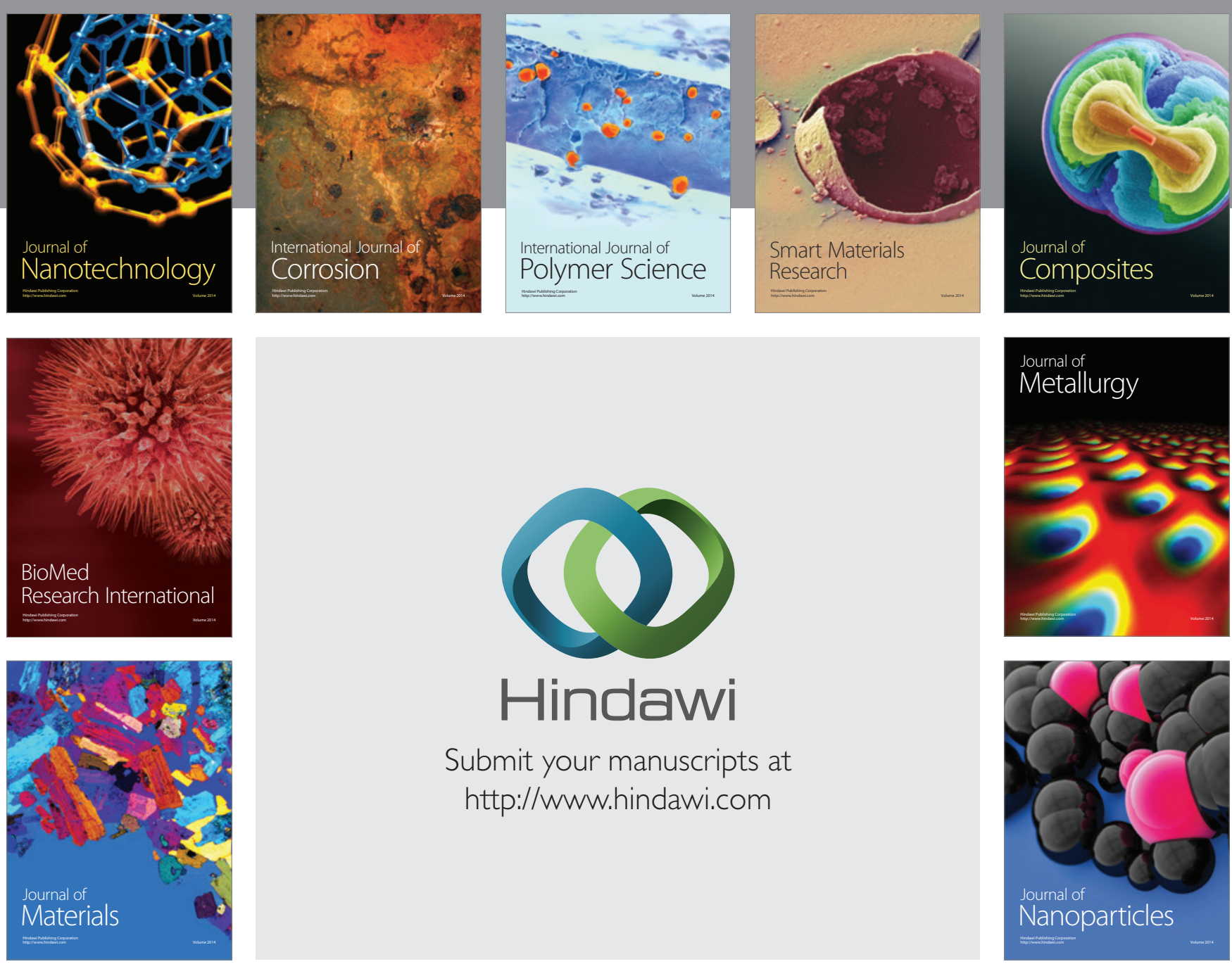

Submit your manuscripts at http://www.hindawi.com
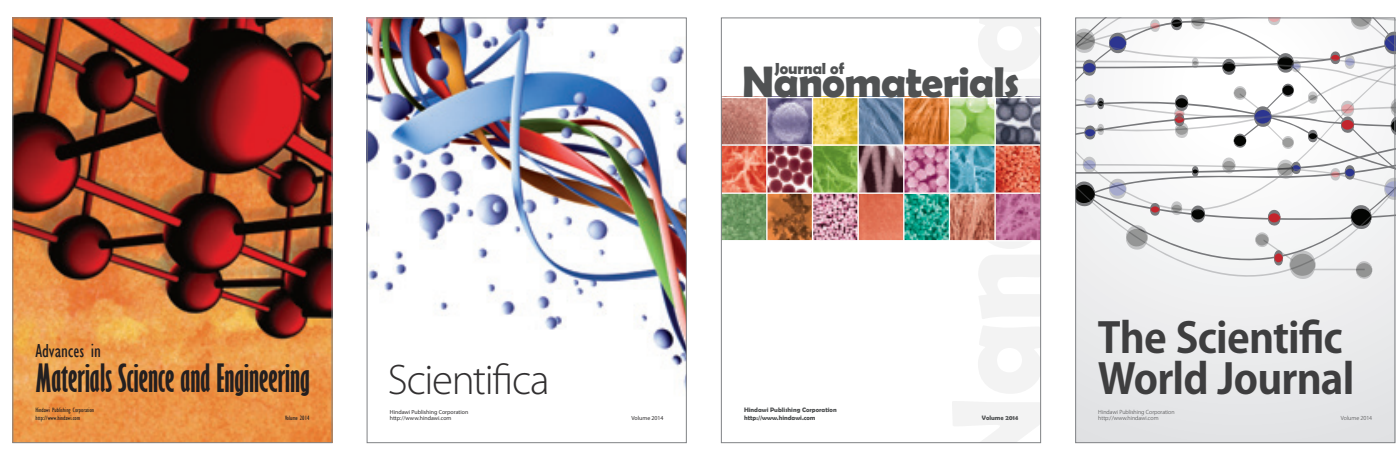

\section{The Scientific World Journal}
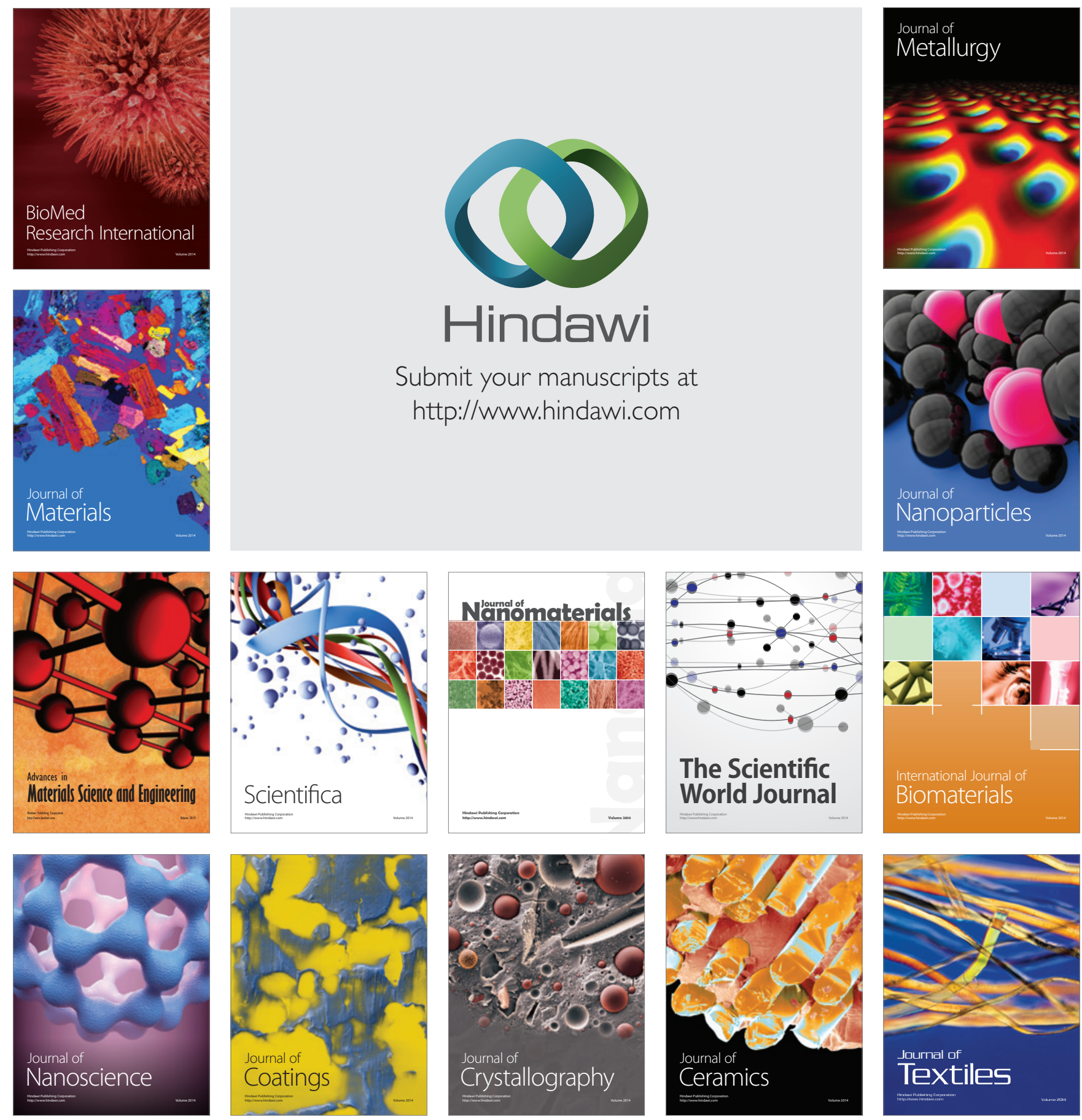